\title{
La lectoescritura como capacidad cognitiva: procesos componentes. Intervención en educación primaria
}

DOI: $10.46932 / \mathrm{sfjdv2n2-005}$

Received in: November 1st, 2020

Accepted in: December 30th, 2020

\author{
Juani González Muñoz \\ Graduated as an elementaryschool teacher, \\ Institution: RG Formación \\ Calle Rosalía de Castro, 44, 30107 Murcia \\ Belén Cánovas Calderón \\ Graduated as an elementaryschool teacher, \\ Institution: RG Formación \\ Calle Rosalía de Castro, 44, 30107 Murcia \\ Rocío Muñoz Melgar \\ Graduated as an elementaryschool teacher, \\ Institution: RG Formación \\ Calle Rosalía de Castro, 44, 30107 Murcia \\ Jose María Rabal Alonso \\ Professor ISEN Centro Universitario \\ Institution: Universidad de Murcia \\ Calle Campus Universitario, 12, 30100 Murcia \\ E-mail: josemaria.rabal@um.es
}

\section{RESUMEN}

En el presente artículo se tratarán aspectos relevantes relacionados con la lectoescritura como capacidad cognitiva. La competencia lectora es la capacidad de las personas de poner en práctica su comprensión lectora de una manera eficaz. La comprensión lectora es la habilidad de las personas de poder entender lo que nos dice un texto escrito de una manera objetiva. Para esto se deben desarrollar distintas habilidades necesarias como el reconocimiento de palabras escritas y de comprensión lectora, y se deben de tener en cuenta distintos procesos implicados en la escritura como son la elaboración y la producción de un texto. A su vez, la memoria operativa controla y almacena la información, por lo que puede explicar diversas complicaciones y dificultades relacionadas con la escritura. Por último, cabe destacar que la lectura y la escritura son procesos relacionados y según Utha Frith (1985) citado por Ramos (2004), para el aprendizaje y enseñanza de la lectoescritura se deben tener en cuenta las etapas logográfica, alfabética y ortográfica.

Palabras clave: didáctica, organización escolar, educación inclusiva, necesidades educativas.

\section{PROCESOS COMPONENTES DE LA ACTIVIDAD LECTOESCRITURA}

\subsection{INTRODUCCIÓN A LA LECTURA.}

Las habilidades relacionadas con la lectura deben ser aprendidas, al contrario que el lenguaje oral que se adquiere de forma natural. La competencia lectora consiste en la capacidad de construir 
conocimientos a través de la lectura y lograr un aprendizaje significativo. En esta tarea, el lector extrae, interpreta y reflexiona sobre la información y el proceso.

La lengua escrita es una forma de comunicación, que surgió hace 5.000 años para perpetuar la información en el tiempo. Se hace necesario que los procesos que se llevan a cabo en esta actividad se realicen de forma automática para liberar espacio en la memoria operativa.

\section{HABILIDADES DE RECONOCIMIENTO DE LAS PALABRAS ESCRITAS}

A través de estas habilidades se permite conocer el significado, la ortografía y la fonología de las palabras. Se llevan a cabo procesos de análisis de la grafía, análisis del significado a través de la léxica y la subléxica y, a su vez, se tienen en cuenta las reglas de conversión grafema-fonema y el uso del alfabeto, entre otras.

\section{LA ESCRITURA COMO ELEMENTO COMUNICATIVO}

Los procesos de escritura y lectura están altamente relacionados, compartiendo algunas estructuras neurobiológicas. Del mismo modo, la actividad de la escritura se puede emplear de forma reproductiva cuando transcribimos información o, por otro lado, de forma productiva expresando pensamientos o ideas.

\section{HABILIDADES DE COMPRENSIÓN LECTORA}

Permiten diferenciar distintas categorías gramaticales en las palabras y sintagmáticas en las oraciones. Según Kintsch (1988), se pueden apreciar diversas habilidades como la comprensión del texto en distintos niveles. En primer lugar, la "microescritura" que consiste en una comprensión superficial del texto, palabras e ideas. Por otro lado, la "macroescritura", una comprensión más profunda del texto, llevando a cabo un aprendizaje a partir de lo que hemos leído, elaborando un resumen del texto con nuestras propias palabras. Por último, habilidades metacognitivas y motivacionales lo que conlleva a que el lector se sienta motivado y sea constante en su tarea.

\section{PROCESOS IMPLICADOS EN LA ESCRITURA}

\subsection{ELABORACIÓN DE LA ESCRITURA.}

Los procesos que se ven involucrados en la escritura tienen un carácter complejo cognitivo y requieren una planificación de ideas que queremos transmitir. Este proceso parte de los conocimientos previos que se tienen sobre el tema a tratar, estableciendo unos objetivos. A su vez, se debe planificar las ideas concretas que van a organizar el texto y el género. Una vez hecho esto, se revisará y corregirá el texto.

Del mismo modo, son procesos de carácter lingüístico, en el que se organizan las ideas mentalmente para, después, plasmarlas en el texto (subproceso sintáctico), teniendo en cuenta la microescritura y la macroescritura. En la elaboración del texto, se tendrán en cuenta elementos sintácticos exclusivos, como 
puede ser el punto, la entonación, etc.

\subsection{PRODUCCIÓN DE LA ESCRITURA.}

Procesos básicos de carácter lingüístico, en los que se plasman las ideas abstractas con palabras (subproceso léxico), mediante dos vías: vía directa e indirecta del sistema semántico. En primer lugar, la vía directa está relacionada con la ortografía arbitraria con acceso al almacén grafémico. En segundo lugar, la vida indirecta, relacionada con la ortografía natural, con acceso al almacén fonémico.

Existen palabras en nuestra lengua que no siguen la ortografía natural, como por ejemplo, cerezazereza, por lo tanto si se tiene en cuenta la vía indirecta que cometerán faltas ortográficas.

Para la producción de la escritura se llevan a cabo distintos movimientos para la elaboración de los grafemas, como son: elegir un código, un tipo de letra, y tener en cuenta el patrón motórico.

\section{MEMORIA OPERATIVA Y COMPETENCIA LECTORA}

La memoria operativa se encarga de controlar y almacenar la información, consiste en un sistema de memoria temporal y permite la capacidad de pensamiento complejo (Baddeley, 2007, 2012; Baddeley y Hitch, 1974). A su vez, almacena procesos metacognitivos de la compresión como el conocimiento previo, estrategias para entender el texto y comprobar su eficacia para nuestra comprensión. Recientes estudios demuestran como la MO predice de una manera más eficaz la comprensión y las habilidades y estrategias de la lectura, entre otras cosas (Alloway y Alloway, 2010).

\section{ESCRITURA Y MEMORIA OPERATIVA}

Teniendo en cuenta los procesos cognitivos, la memoria operativa puede explicar diversas complicaciones relativas a la escritura. Del mismo modo, en esta se desarrollan distintos movimientos para producir los textos, como son: la reflexión, la textualización y la revisión.

\subsection{APRENDIZAJE Y ENSEÑANZA DE LA LECTOESCRITURA}

La lectoescritura es un proceso complejo en el que el estudiante lleva a cabo distintas estrategias, como son observación, identificación, descripción, comparación, etc. (González López, 2018 y González López, 2019). Según Utha Frith (1985), lectura y escritura son habilidades altamente relacionadas. El modelo, según esta autora, se centra en los procesos sintácticos y léxicos. En la misma línea, el desarrollo de estas habilidades, según Utha Frith (1985) citado por Ramos (2004) se lleva a cabo en tres fases:

1) Etapa logográfica.

Los niños de 3 y 4 años tienen una aproximación cercana a la lectura. Esta etapa comienza con la copia y reconocimiento de palabras cotidianas y familiares para ellos (por ejemplo, etiquetas de golosinas o alimentos), y comienzan a escribir garabatos para expresarse. 
2) Etapa alfabética.

Tras la etapa anterior, sigue desarrollando habilidades de lectura, deben apreciar que las palabras están formadas por partes más pequeñas, como las sílabas, para poder representar el fonema en grafía, lo que supone un proceso complejo. Una vez que se decodifica, se mejora la capacidad lectora y, de lo contrario, la lectura puede ser más lenta. El alumnado adquiere reglas de correspondencia y comienza a desarrollar la ortografía natural.

3) Etapa ortográfica.

En esta etapa se desarrolla un léxico interno ya que el alumnado lee los mismos vocablos varias veces y, al mismo tiempo, con la lectura mejora la ortografía. Se presenta un gran avance entre los siete u ocho años por el aumento del léxico visual para llevarlo al lenguaje oral. Durante esta etapa se desarrolla la vía léxica, se evitan reglas de conversión y el alumnado puede escribir palabras rápidamente.

\section{CONCLUSIÓN}

La comunicación es uno de los procesos que más influyen en el comportamiento de las personas, y el objetivo del aprendizaje de la lectoescritura es ser competentes en la actividad de la comunicación.

La lectura es una fuente de aprendizaje que nos permite estar conectados con nuestro alrededor, nos genera nuevos conocimientos y nos ayuda a lograr un aprendizaje significativo. La escritura es una herramienta para reflexionar sobre nuestro conocimiento y pensamiento y nos permite organizarlo. Es esencial saber por qué y para qué leemos, que desarrollemos y pongamos en práctica diversas estrategias cognitivas para facilitar la comprensión lectora. Para conseguir el aprendizaje y enseñanza de la lectoescritura es necesario que se desarrollen habilidades para la comprensión para poder formar lectores activos, que entiendan, escriban y comuniquen lo que pueden llegar a escuchar o leer.

Los docentes deben conocer a sus alumnos, sus necesidades e intereses, para que, de este modo, puedan ayudarles en este proceso de aprendizaje, aplicando estrategias y herramientas necesarias y específicas en los estudiantes de una manera crítica y reflexiva. 


\section{REFERENCIAS}

Alloway, T. P. y Alloway, R. G. (2010). Investigating the predictive roles of working memory and IQ in academic attainment. Journal of Experimental Child Psychology, 106(1), 20-29

Alonso, J. M. R., \& Romero, M. G. (2018). Disortografía. In IV Congreso Virtual Internacional sobre Innovación Pedagógica y Praxis Educativa INNOVAGOGÍA 2018: libro de actas: 20, 21 y 22 de marzo 2018 [resúmenes] (p. 301). AFOE. Asociación para la Formación, el Ocio y el Empleo.

Baddeley, A. D. (2007). Working memory, thought, and action. Oxford, UK: Oxford University Press.

Baddeley, A. D. y Hitch, G. (1974). Working memory. En G. A. Bower (Ed.), The psychology of learning and motivation (Vol. 8, pp. 47-89). New York: Academic.

Baddely, A. D. (2012). Working Memory: Theories, Models and Controversies. Annual Review of Psychology, 63, 1-29.

Frith, U. (1985). Fases de desarrollo de la escritura de palabras del modelo evolutivo de Utha Frith. Recuperado de: http://www. ladislexia. net/desarrollo-de-la-escritura.

González López, M. (2018). Actividades para aprender a leer y a escribir en español (libro de texto). Chihuahua, México. En: https://uach-mx.academia.edu/MarielaGonz\%C3\%A1lezL\%C3\% B3pez.

González López, M. (2019). La enseñanza de habilidades de pensamiento y de la comprensión lectora en estudiantes de bajo rendimiento escolar. Areté.

Kintsch, W. (1988). The role of knowledge in discourse comprehension: A construction-integration model. Psychological Review, 95(2), 163-182.

Ramos, S.J. L.,(2004). Enseñar a leer a los alumnos con discapacidad intelectual: Una reflexión sobre la práctica. Revista Iberoamericana de Educación.

Romero, M. G., Alonso, J. M. R., \& Romero, J. G. (2020). Aproximación conceptual a la dislexia en las aulas de Educación primaria. Brazilian Journal of Development, 6(4), 20157-20165.

Romero, M. G., Alonso, J. M. R., \& Romero, J. G. (2020). Aproximación conceptual a la disortografía. Aportaciones docentes. Brazilian Journal of Development, 6(4), 18814-18820. 


\section{$\underline{\text { ACTIVIDADES }}$}

A continuación, presentamos un método de enseñanza de la lectoescritura basado en el modelo de escritura por etapas de Utha Frith (1985). Utha Frith separó el proceso de la lectoescritura en tres etapas: la etapa logográfica, la etapa alfabética y la etapa ortográfica. En primer lugar, durante la primera etapa las palabras son distinguidas como unidades independientes y del mismo modo, se identifican en basea esquemas muy característicos. Durante la segunda etapa, empiezan a analizar laspalabras según las letras que las componen y a su vez, se determinan algunas reglasde correspondencia con los fonemas. Por último, en la última etapa se lleva a cabo la construcción de unidades de reconocimiento por encima del nivel alfabético lo cualpermite el reconocimiento de la composición morfológica de las palabras instantáneamente. Estas actividades tendrán como tema principal el cuerpo.

\section{Primera actividad}

Para la primera etapa utilizaremos unas tarjetas en las que se presentarán imágenes del cuerpo humano, como pueden ser las piernas, brazos, manos, etc. Estas tarjetas se mezclarán con distintas imágenes de objetos cotidianos y los alumnos solo podrán escoger aquellas tarjetas que tengan relación con el cuerpo humano. Los alumnos podrán asociar las primeras palabras al leerlas en voz alta una y otra vez.

Para la segunda etapa utilizaremos esas mismas tarjetas a modo de juego. El juego consistirá en lo siguiente: el alumnado deberá levantar tarjetas que estarán boca abajo. De uno en uno irán levantando y quién levante una de las tarjetas del cuerpo humano, saldrá a la pizarra a hacer un dibujo y escribir el nombre de lo que le ha tocado, así hasta terminar con todas.

Por último, en la tercera etapa, solo tendremos las tarjetas del cuerpo humano. Los niños formarán grupos de tres y, cada uno de los grupos tendrá una tarjeta distinta. Estas serán: pierna, brazo, mano, pie y cuello.

Mano:

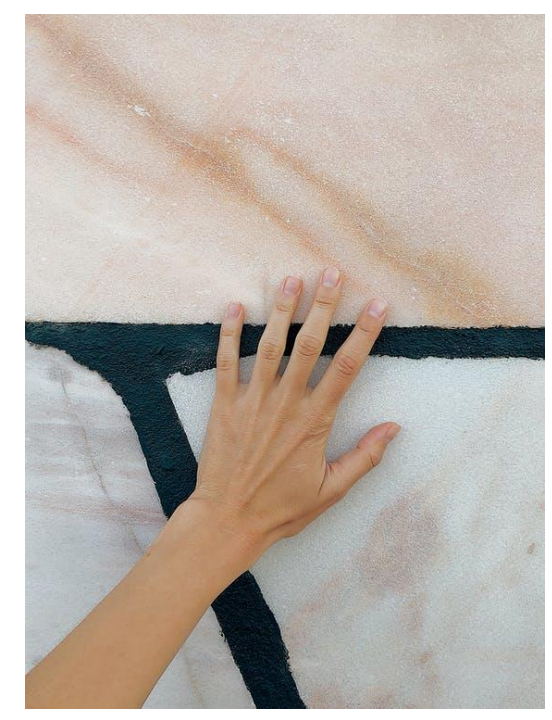


Cuello:

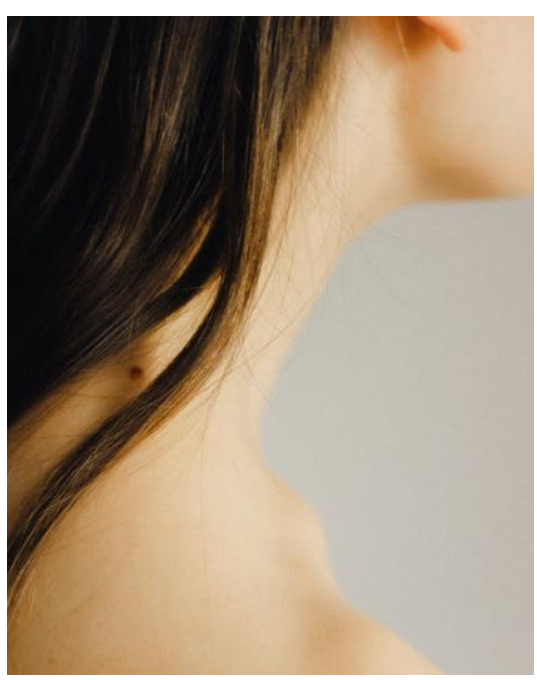

Piernas:

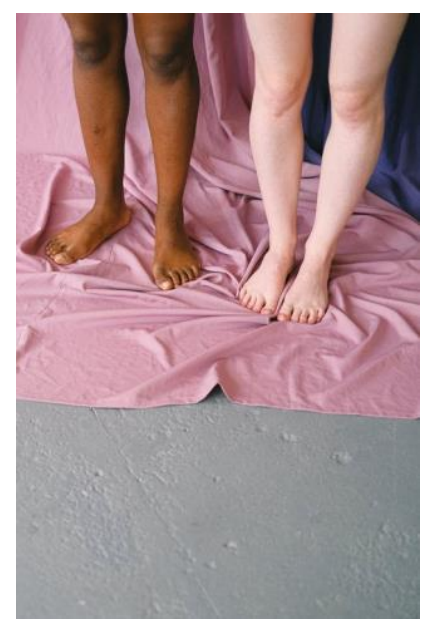

Pie:

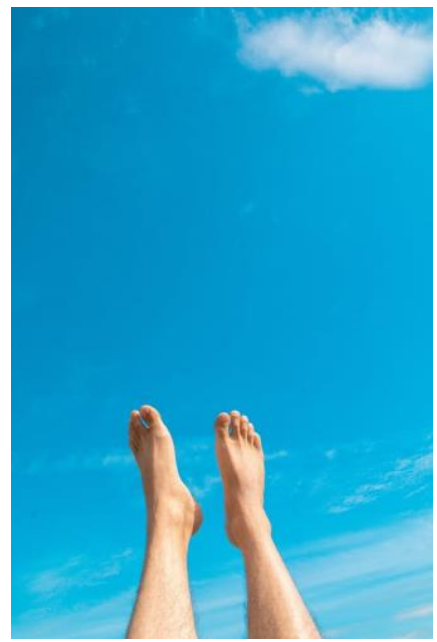


Brazo:

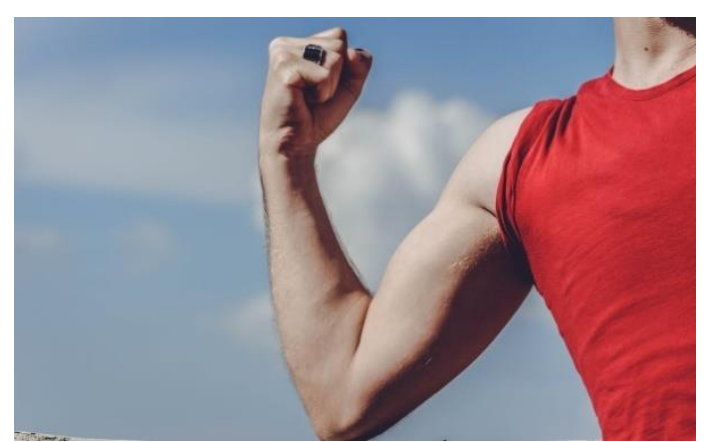

Estas tarjetas se repartirán de manera aleatoria para poder comenzar la siguiente actividad. Los grupos deberán realizar un cómic en una cartulina, en la que el elemento protagonista deberá ser la imagen de la tarjeta. Es una manera de acercar a los niños a la lectura y escritura ya que serán ellos mismos los creadores del texto e imágenes, fomentando la libertad de expresión y creación al mismo tiempo.

\section{ETAPA LOGOGRÁFICA:}

- Lectura

Nombre: Tu cuerpo

\section{$\underline{\text { Segunda actividad }}$}

Actividad: El alumno deberá observar las imágenes que les aparecen en la ficha yrellenar los huecos, estos huecos pertenecen a las diferentes partes del cuerpo.
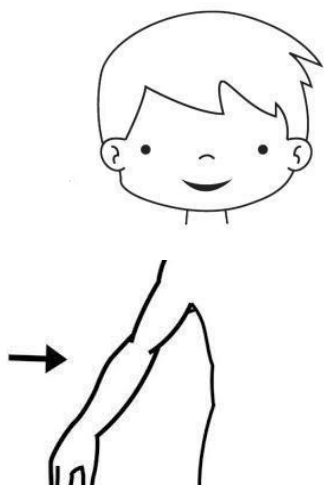

La___está encima de los hombros. puedo nadar.

Con las podemos andar.

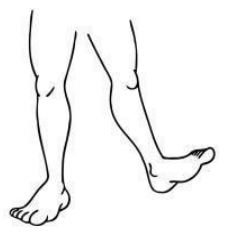

Hemos elegido esta activada ya que al estar en la primera etapa los alumnos al ver los dibujos sabrán a qué parte del cuerpo se refiere, gracias a esto podemos trabajartanto le lectura como la escritura de una manera más sencilla

Recursos: Ficha para todos los alumnos 
Nombre: Ordena tu cuerpo.

\section{Tercera actividad}

Actividad: El alumno deberá de recortar las sílabas proporcionadas por el profesor,para posteriormente ordenarlas y formar palabras, para colocarlas una vez formada la palabra debajo de su imagen correspondiente.

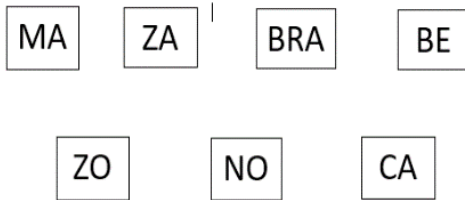

Hemos escogido este tipo de actividad porque podemos trabajar la lectura de una manera más dinámica, debido a que según vayan formando las palabras las van a irleyendo para saber con qué imagen va, y al tratarse de la etapa logográfica nos parece la más adecuada.

Recursos: Una ficha de sílabas por alumno, una ficha de imágenes por alumno, y tijeras.

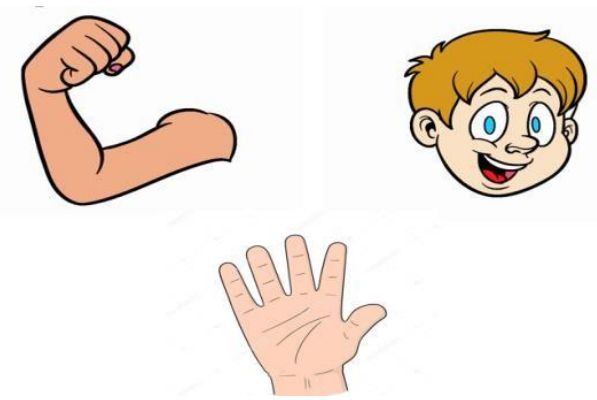

\section{- Escritura}

Nombre: Conoce todas las partes.

\section{Cuarta actividad}

Actividad: El alumno deberá de sacar de una caja una foto, decir que aparece en esa foto, y escribirlo en su libreta, y en la pizarra, para que así el profesor compruebesi lo ha escrito bien. Hemos escogido esta actividad porque es una manera de que los alumnos practiquen la escritura de una manera diferente y más fácil, ya que también entran en juego lasimágenes. Recursos: Imágenes de las diferentes partes del cuerpo plastificadas, una caja, lápiz, y libreta. 


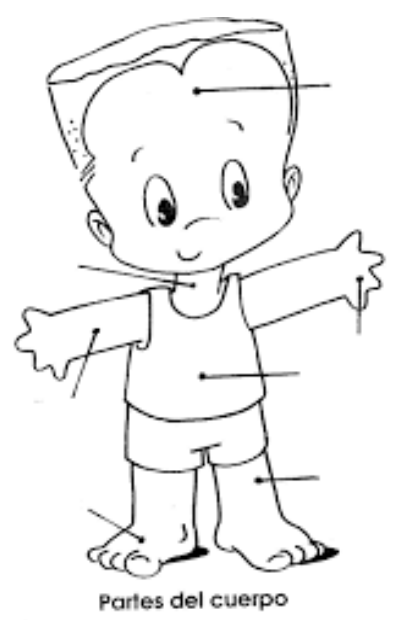

Nombre: Mi cuerpo.

\section{Quinta actividad}

Actividad: Cada alumno deberá de salir a la pizarra a escribir cada una de las partesdel cuerpo que se encuentren señaladas en una lámina que anteriormente haya colocado el profesor en la pizarra, posteriormente deberán de rellenar una ficha conlas mismas característica.

Recursos: Lámina del cuerpo humano, rotulador (para escribir sobre la lámina), unaficha para cada alumno, lápiz.

ETAPA ALFABÉTICA:

- Lectura

\section{Sexta actividad}

Nombre: Intrusa.

Actividad: Esta actividad consiste en que entre muchas palabras relacionadas conel cuerpo humanas el alumnado sepa identificar cual es la que no lo es.

Con esta actividad los alumnos tendrán que leer detenidamente cada una de laspalabras para poder identificarla con el cuerpo.

MANO PIE SILLA OJO

Recursos: Para esta actividad el alumnado recibirá una ficha proporcionada por laprofesora o profesor.

\section{$\underline{\text { Séptima actividad }}$}

Nombre: ¿Cuál es?

Actividad: Le proporcionaremos al alumnado una ficha en la que aparezca la descripción de cualquier palabra relacionada con el cuerpo humano y le daremos tresopciones, tendrán que seleccionar la palabra correcta.

Sirve para decirle a mama o papa si me duele la cabeza.

BOCA OREJA OJO

Recursos: Ficha proporcionada por la profesora o profesor. 


\section{Octava actividad.}

Nombre: ¡Palabras nuevas!

Actividad: El alumnado le dicta palabras a la profesora o profesor, que esta debe apuntar en la pizarra. Una vez haya varias palabras en la pizarra, el alumnado deberáde apuntar en su cuaderno y formar nuevas palabras relacionadas con el cuerpo conlas que ya hay, por ejemplo, si tengo MAMÁ y también tengo NOVIA separamos $\underline{\text { MAy }} \underline{\text { NO }}$ unidas tenemos MANO. Cada palabra nueva que ellos formen deberán de escribirla y una vez acabada la actividad hacer una puesta en común de todas las palabras.

Con esta actividad queremos aumentar también la actividad del niño, a su vez que también identificar si han escrito palabras relacionadas con el cuerpo o no lo han hecho pero ellos creen que si y corregirlo en la puesta en común.

Recursos: Cuaderno.

\section{Novena actividad.}

Nombre: Sopa de letras

Actividad: Los alumnos deberán localizar las siete partes del cuerpo que seencuentran en la sopa de letras de la derecha. Con esta actividad queremos alcanzar el objetivo del reconocimiento y el análisis de las palabras que aparecen en el ejercicio. Hemos escogido esta actividad para que el alumnado pueda aprender jugando y corresponde al segundo ciclo de Educación Primaria ya que es necesario que los alumnos consigan analizar y localizar las palabras para llevar a cabo el ejercicio. Cuando encuentren una palabra deberán escribirla en su cuaderno.

$\begin{array}{lllllll}R & M & A & N & O & O & H \\ N & O & A & E & D & \text { I } & \text { L } \\ \text { A } & R & D & O & O & E & E \\ R & E & C & \text { I } & \text { P } & \text { I } & \text { C } \\ \text { I } & \text { J } & \text { O } & \text { E } & \text { L } & \text { I } & \text { U } \\ \text { Z } & \text { A } & H & \text { U } & \text { R } & \text { L } & \text { E } \\ \text { E } & R & D & E & D & O & A\end{array}$

Recursos: Para esta actividad se le entregará a cada uno de los alumnos una ficha con la 
sopa de letras, un lápiz y un cuaderno.

CODO MANO DEDO RODILLA PIE NARIZ OREJA

\title{
ETAPA ORTOGRÁFICA:
}

- Lectura

\section{Décima actividad.}

Nombre: Adivina la parte de tu cuerpo.

Actividad: Los alumnos deberán leer una serie de adivinanzas, con la finalidad de descubrir a qué parte de su cuerpo se corresponde. Para ello leeremos las adivinanzasen voz alta, después los alumnos podrán hacer preguntas sobre aquellas palabras que no entienden y finalmente tras una lectura comprensiva de la adivinanza deberánaveriguar de qué parte se trata. Las adivinanzas serán las siguientes:

\author{
Uno chiquito, \\ Dos igualitos, \\ Uno largo y flaco \\ $Y$ el otro gordazo.
Una señora aseñorada,
Siempre va en coche
$Y$ siempre va mojada. \\ Con ella vives, \\ Con ella hablas \\ Con ella expresas \\ $Y$ hasta bostezas. \\ Unas son redondas \\ Otras son cuadradas \\ Unas piensan mucho \\ Otras casi nada. \\ Si los abro veo, \\ Si los cierro sueño.
}

Hemos elegido esta actividad, para realizarla en el tercer ciclo, ya que consideramosque en la lectura de las adivinanzas debes hacer una lectura comprensiva y reflexivadel texto para poder resolverla. Al estar en la etapa ortográfica los alumnos deben de haber interiorizado el proceso lector, y como consecuencia esto les ayudará a entender el contexto y el contenido del texto.

Recursos: Para esta actividad vamos a necesitar tantas fichas como alumnos tengamos en el aula.

Nombre: Las parejas.

\section{Undécima actividad.}

Actividad: Se le entregarán veinte cartas a cada grupo (cuatro o cinco alumnos porgrupo), en las cartas habrán diez nombres diferentes de partes de cuerpo (dos de cada). Dicho grupo a su vez se agruparán por parejas de modo que se enfrenta unapareja a otra. En primer lugar, pondrán todas 
las cartas boca arriba y leerán las cartas (10 segundos) y a continuación las pondrán boca abajo. Los alumnos deberánencontrar las parejas de cartas y la pareja que consiga más cartas será la ganadora.

Esta actividad se llevará a cabo en el segundo ciclo de Educación Primaria ya que tendrán la dificultad de que es necesaria una lectura rápida de las cartas de manerainstantánea.

Recursos: 20 cartas con nombres de partes del cuerpo para cada grupo.

\section{- Escritura}

\section{Duodécima actividad.}

Nombre: Vuelta al pasado.

Actividad: Los alumnos deberán traer a clase una foto de cuando eran pequeños y una actual, con estas dos fotos deberán observar los cambios que han sufrido físicamente, y hacer una comparación escrita de los cambios que observan. Finalmente, saldrán con las dos fotos a exponer su transformación a los compañeros

Hemos elegido esta actividad ya que nos parece una forma de mezclar la redacción con los cambios físicos que se están produciendo en su cuerpo, y que al fin y al cabohablen de las diferentes partes de su anatomía para complementar con la temática del cuerpo humano.

Recursos: Los alumnos deberán traer una foto de la actualidad y otra de cuando eran pequeños.

\section{Decimotercera actividad.}

Nombre: Lápiz arriba.

Actividad: A los alumnos se le entregará un folio, uno a cada uno, y se sacará un papel por sorteo el cual tendrá escrita una letra. Los alumnos deberán escribir el máximo de palabras correspondientes a partes del cuerpo que empiecen o contengandicha letra. Tendrán noventa segundos y una vez finalizado el tiempo el docente dirá“ ;Lápiz arriba!” y los alumnos no podrán escribir más. Contabilizarán las palabras escritas y el alumno que al finalizar el juego tenga más palabras será el ganador. Elnúmero de rondas dependerá del tiempo que disponga el docente ya que esta actividad se puede acortar y alargar como se quiera.

Recursos: un folio y un lápiz para cada alumno, una caja con papelitos en su interior(un papel con cada letra del abecedario) para el sorteo. 